\title{
Early cardiotoxicity after adjuvant concomitant treatment with radiotherapy and trastuzumab in patients with breast cancer
}

\author{
Tanja Marinko1, Simona Borstnar², Rok Blagus³ ${ }^{3}$ Jure Dolenc ${ }^{4}$, Cvetka Bilban-Jakopin ${ }^{1}$ \\ ${ }^{1}$ Department of Radiation Oncology, Institute of Oncology Ljubljana, Ljubljana, Slovenia \\ ${ }^{2}$ Department of Medical Oncology, Institute of Oncology Ljubljana, Ljubljana, Slovenia \\ ${ }^{3}$ Department of Cardiology, University Medical Centre Ljubljana, Ljubljana, Slovenia \\ ${ }^{4}$ Institute for biostatistics and medical informatics, University of Ljubljana, Slovenia
}

Radiol Oncol 2018; 52(2): 204-212.

Received 4 December 2017

Accepted 12 December 2017

Correspondence to: Assist. Tanja Marinko, M.D., Ph.D., Department of Radiation Oncology, Institute of Oncology Ljubljana; Zaloška 2, 1000 Ljubljana, Slovenia. Phone: +386 15879 550; Fax: +386 15879 400; Email: tmarinko@onko-i.si

Disclosure: No potential conflicts of interest were disclosed

Background. The purpose of the study was to find out whether there is a difference in the early parameters of cardiotoxicity (left ventricular ejection fraction [LVEF] and N-terminal pro-B-type natriuretic peptide [NT-proBNP]) between the two groups of patients: the patients treated for left breast cancer (left breast cancer group) and those treated for the right breast cancer (right breast cancer group), after the treatment had been completed.

Patients and methods. The study included 175 consecutive patients with human epidermal growth factor receptor-2 (HER2) positive early breast cancer, treated concurrently with trastuzumab and radiotherapy (RT), between June 2005 and December 2010. Echocardiography with LVEF measurement was performed before adjuvant RT (LVEF $)_{0}$ and after the completed treatment $\left(\operatorname{LVEF}_{1}\right)$. After the treatment NT-proBNP measurement was done as well. The difference $(\Delta)$ between $L V E F_{0}$ and $L V E F_{1}$ was analysed $\left(\triangle \mathrm{LVEF}=\mathrm{LVEF}_{0}-\mathrm{LVEF}_{1}\right)$ and compared between the two groups.

Results. There were 84 patients in the left and 91 in the right breast cancer group. Median observation time was 57 (37-71) months. Mean $\triangle$ LVEF (\%) was $-1.786 \%$ in the left and $-2.607 \%$ in the right breast cancer group $(p=0.562$, Cl: -2.004 to 3.648). Median NT-proBNP were $111.0 \mathrm{ng} / \mathrm{l}$ in the left and $90.0 \mathrm{ng} / \mathrm{l}$ in the right breast cancer group $(\mathrm{p}=0.545)$. Echocardiography showed that the patients in the left breast cancer group did not have significantly worse systolic and diastolic left ventricular function in comparison with the patients in the right breast cancer group, but, they had higher incidence of pericardial effusion (9 [11\%] vs. $1[1 \%])(p=0.007)$.

Conclusions. We did not find any significant differences in the early parameters of cardiotoxicity (LVEF, NT-proBNP) between the observed groups. Patients who received left breast/chest wall irradiation had higher incidence of pericardial effusion.

Key words: trastuzumab; breast cancer; Radiotherapy; cardiotoxicity; echocardiography

\section{Introduction}

The advent of trastuzumab, a humanized monoclonal antibody against the extracellular domain of human epidermal growth factor receptor-2 (HER2), represented a major breakthrough in the treatment of patients with HER2-positive breast cancer. Long term follow-up from the initial large adjuvant tri- als with trastuzumab continue to show some remarkably positive results. ${ }^{1}$ The current standard adjuvant systemic treatment of early HER2-positive breast cancer consists of chemotherapy (CT) plus 12 months of trastuzumab, with or without endocrine therapy. ${ }^{2-4}$ The patients treated with adjuvant radiotherapy (RT) of the breast or chest wall receive trastuzumab concurrently with RT. Treatment with 
trastuzumab results in a small to modest cardiotoxicity risk. ${ }^{5-7} \mathrm{RT}$ could be cardiotoxic as well. ${ }^{8-10}$ Longterm effects of concomitant treatment with trastuzumab and RT have not yet been known, the most important of which is the issue of cardiotoxicity.

Reduced left ventricular ejection fraction (LVEF) and elevated $\mathrm{N}$-terminal pro-B-type natriuretic peptide (NT-proBNP) levels represent early parameters of cardiotoxicity. LVEF is the golden standard for monitoring cardiac function in patients receiving cardiotoxic therapy. ${ }^{11}$ Trastuzumab-related cardiotoxicity is most often manifested by an asymptomatic decrease in LVEF, and less often by clinical heart failure. ${ }^{12-14}$ NT-proBNP represents a sensitive biomarker for both: systolic and diastolic heart failure, not just as a diagnostic tool, but also as a prognostic tool. ${ }^{15}$ Elevated levels can be detected early in the asymptomatic stage of the disease, or in patients with the preserved ejection fraction. ${ }^{16}$ Changes in NT-proBNP usually occur earlier than changes in LVEF. ${ }^{17}$

There are two widely used methods for measuring LVEF: radionuclide ventriculography and echocardiography. The first method provides solely the information regarding the LVEF, while the second one provides also the information concerning chamber dimensions, heart valves, and pericardium. This data is very important because a reduction in LVEF is not that sensitive and it occurs later than left ventricular diastolic dysfunction. Some patients with heart failure never develop ventricular systolic dysfunction (heart failure with preserved ejection fraction). ${ }^{17-19}$

The main purpose of this study was to find out whether there is a significant difference in the early parameters of cardiotoxicity between the two groups of patients: those who received adjuvant trastuzumab and concurrent postoperative RT to the left (left breast cancer group) or to the right (right breast cancer group) breast/chest wall, after the completed treatment.

The study was designed as an equivalence study. Our hypothesis was that there were no significant differences between the left breast cancer and the right breast cancer group regarding some early cardiotoxicity parameters (LVEF and NT-proBNP).

\section{Materials and methods}

\section{Patients and treatment}

In a prospective observational monocentric population study, we included 175 consecutive patients with HER2-positive breast cancer (stage I-III) with- out disease recurrence, who received adjuvant treatment with trastuzumab and RT to the breast/ chest wall between June 2005 and December 2010 at the Institute of Oncology in Ljubljana.

All patients were treated according to the clinical guidelines, namely with surgery, CT, endocrine therapy in case of hormone receptor positive disease, trastuzumab, and RT. Trastuzumab treatment started before RT or on the first day of RT at the latest. Altogether, 203 consecutive patients with HER2-positive breast cancer were invited to participate in the study, among them 28 patients refused to be involved in the study. Informed consent was obtained from all individual participants included in the study. The study was internationally registered at ClinicalTrial.gov (identifier NCT 01572883), and it was approved by the Republic of Slovenia National Medical Ethics Committee.

In the study framework, between December 2011 and July 2012, after the treatment with trastuzumab had been completed, we performed clinical examinations, echocardiographic measurements of LVEF, and measurements of NT-proBNP levels in all patients. Baseline LVEF was determined either by means of echocardiography or by radionuclide ventriculography. Before the clinical examination took place patients had fulfilled the questionnaires about smoking, concomitant diseases, and problems related to cardio-vascular diseases. All other data were collected from the patients' records. Patients were classified in New York Heart Association (NYHA) classes, according to the NYHA classification, as well as in World Health Organisation (WHO) performance classes, according to the WHO classification.

\section{Systemic treatment}

The criteria for the adjuvant treatment with trastuzumab regarding tumour, nodal stage and cardiac function were the same as in pivotal adjuvant trials: tumours larger than $2 \mathrm{~cm}$ if node negative disease, any tumour size if node positive disease, WHO performance status zero or one, no serious concomitant cardiac disease, and treatment with adjuvant $\mathrm{CT} .^{4}$

\section{Loco regional treatment}

According to clinical guidelines patients were operated with either breast conservation surgery or mastectomy and either sentinel node biopsy or axillary dissection. After the operation and CT they were irradiated on the Cobalt machine or on the 
linear accelerator. Two-dimensional RT (2D RT) or three-dimensional conformal RT (3D CRT) were mostly used. Some of the patients received electronbeam chest wall irradiation, sometimes in combination with concomitant photon-beam irradiation of the periclavicular region (regional RT). Whole breast RT was required in all patients who underwent breast cancer surgery. In addition to the irradiation of the breast/thoracic wall all patients with 4 or more positive axillary lymph nodes also received regional RT. Parasternal lymph nodes were not specifically included in the irradiated area.

Patients were irradiated with a total dose (TD) $=$ $25 \times 2$ Gy, 5 fractions per week. A minority received RT with TD $=17$ or $18 \times 2.5$ Gy, 5 fractions per week. RT was performed 3 or more weeks after CT had been completed and concurrently with trastuzumab treatment as well as hormonal therapy in case of hormone receptor positive breast cancer.

\section{Echocardiography and radionuclide ventriculography}

At the beginning of the primary systemic therapy baseline echocardiography was performed at different clinical institutions according to the shortest waiting time for the examination. Contrary to this, all control echocardiographies were performed in one institution (Department of Cardiology, University Medical Centre Ljubljana) by three cardiologists, and they were carried out on the same device (Aloka SSD- $\alpha 10$, Tokyo, Japan). Conventional and tissue-Doppler echocardiography was performed on each patient. ${ }^{20,21}$ Normal range for LVEF was $50 \%$ or more.

All radionuclide ventriculographs were performed at the Institute of Oncology in Ljubljana (Gamma Cam Siemens; erythrocytes were labelled with in vivo method, activity 740-952 MBq) Normal range for LVEF was $50 \%$ or more. LVEF was calculated with the programme Intermedical/ Medicview.

\section{NT-proBNP}

NT-proBNP was determined with the analyser Cobas e 411 (Roche). According to the instructions of the manufacturer, the values of the NT-proBNP below $125 \mathrm{ng} / \mathrm{l}$ exclude heart dysfunction.

\section{Pathology methods}

HER2 immuno histochemistry (IHC) expression was scored as follows: 0 , no staining or faint mem- brane staining in $\leq 10 \%$ of tumour cells; $1+$, incomplete membrane staining that is faint perceptible in $>10 \%$ of tumour cells, $2+$, incomplete and/or weak to moderate membrane staining in $>10 \%$ of tumour cells or complete and intense staging in $\leq 10 \%$ of tumour cells; and 3+, complete, intense circumferential membrane staining in $>10 \%$ of tumour cells. HER2 scores of 0 and $1+$ were considered negative. All IHC2+ tumours were tested for gene amplification by fluorescent in situ hybridization (FISH). HER2 IHC 3+ and FISH-amplified tumours were considered positive.

\section{Statistical methods}

The study was designed as an equivalence study. For the purpose of the analysis the patients were divided into two groups: (1) left breast cancer group: patients irradiated on the left side of the chest (breast cancer of the left breast) and (2) right breast cancer group: patients irradiated on the right side of the chest (breast cancer of the right breast).

In both group we compared the difference between LVEF, measured at the beginning of the adjuvant systemic therapy $\left(\mathrm{LVEF}_{0}\right)$, and LVEF measured after the treatment with trastuzumab $\left(\mathrm{LVEF}_{1}\right)$ had been completed. The difference between the two measurements was marked as $\triangle \mathrm{LVEF}=\mathrm{LVEF}_{0}$ $\mathrm{LVEF}_{1}$ and we made comparisons between the two groups. A 95\% confidence interval for the difference of means (CI) was estimated. Groups were labelled as equivalent if $95 \% \mathrm{CI}$ did not include $\triangle \mathrm{LVEF}$ of 10 percentage points, but it included the value 0 .

In calculating the necessary sample size we assumed that there were no differences in the population between the investigated groups, and that the standard deviation of the difference of $\triangle \mathrm{LVEF}$ would be 10 percentage points. The level of significance was set to $5 \%$ and the desired power to at least $80 \%$. We considered the difference $\triangle$ LVEF of 10 percentage points or less as clinically irrelevant. The calculation using PASS (version 12) showed that under these assumptions the equivalence study enrolling 20 patients per group would have $86 \%$ power. In addition to the primary objective we, namely, wanted to analyse also echocardiographic parameters at the control examination after the completed treatment with trastuzumab and RT. The data is presented as mean (standard deviation, SD) or median (interquartile range Q1-Q3) for continuous variables as appropriate, and number (\%) for categorical variables.

The difference between the groups (the left breast cancer group and the right breast cancer 
TABLE 1. Patients and tumour characteristics, concomitant diseases

\begin{tabular}{|c|c|c|c|c|c|}
\hline & & $\begin{array}{c}\text { All } \\
\mathrm{N}=175(100 \%)\end{array}$ & $\begin{array}{l}\text { Left BC group } \\
\mathrm{N}=84(48 \%)\end{array}$ & $\begin{array}{l}\text { Right BC group } \\
\mathrm{N}=91(52 \%)\end{array}$ & $\mathrm{p}$ value \\
\hline Age in years (Median [Q1-Q3]) & & $58(49-64)$ & $59(52-67)$ & $55(46-63)$ & 0.0096 \\
\hline Menopause status & $\begin{array}{l}\text { Premenopause } \\
\text { Pomenopause }\end{array}$ & $\begin{array}{l}90(51.4 \%) \\
85(48.5 \%)\end{array}$ & $\begin{array}{l}38(45.2 \%) \\
46(54.8 \%)\end{array}$ & $\begin{array}{l}52(57.1 \%) \\
39(42.9 \%)\end{array}$ & 0.155 \\
\hline Histological type & $\begin{array}{c}\text { Ductal invasive } \\
\text { Lobular invasive } \\
\text { Other }\end{array}$ & $\begin{array}{l}168(96 \%) \\
4(2.3 \%) \\
3(1.7 \%)\end{array}$ & $\begin{aligned} 81 & (96.4 \%) \\
2 & (2.4 \%) \\
1 & (1.2 \%)\end{aligned}$ & $\begin{aligned} 87 & (95.6 \%) \\
2 & (2.2 \%) \\
2 & (2.2 \%)\end{aligned}$ & 1 \\
\hline Histo-pathological grade & $\begin{array}{l}G 1 \\
G 2 \\
G 3\end{array}$ & $\begin{array}{c}2(1.1 \%) \\
48(27.4 \%) \\
125(71.5 \%)\end{array}$ & $\begin{array}{c}0 \\
21(25 \%) \\
63(75 \%)\end{array}$ & $\begin{array}{c}2(2.2 \%) \\
27(29.7 \%) \\
62(68.1 \%)\end{array}$ & 0.337 \\
\hline Hormonal receptors & $\begin{array}{c}\text { ER positive } \\
\text { PR positive } \\
\text { ER in PR negative }\end{array}$ & $\begin{array}{l}97(55.4 \%) \\
82(46.8 \%) \\
73(41.7 \%)\end{array}$ & $\begin{array}{l}53(63 \%) \\
43(51.2 \%) \\
28(33.3 \%)\end{array}$ & $\begin{array}{l}44(48.3 \%) \\
39(42.8 \%) \\
45(49.4 \%)\end{array}$ & 0.851 \\
\hline \multirow[t]{5}{*}{ Concomitant disease } & Smoking & $33(19 \%)$ & $13(15 \%)$ & $20(22 \%)$ & 0.365 \\
\hline & Arterial hypertension & $35(20 \%)$ & $21(25 \%)$ & $14(15.4 \%)$ & 0.161 \\
\hline & Diabetes & $3(1.7 \%)$ & $3(3.4 \%)$ & 0 & 0.108 \\
\hline & Hyperlipidemia & $30(17.1 \%)$ & $16(19 \%)$ & $14(15.4 \%)$ & 0,658 \\
\hline & Known heart disease* & $4(2.3 \%)$ & $1(1.2 \%)$ & $3(3.3 \%)$ & 0.621 \\
\hline
\end{tabular}

$\mathrm{BC}=$ breast cancer; $\mathrm{ER}=$ estrogens receptor; $\mathrm{PR}=$ progesterone receptor; $\mathrm{Q} 1-\mathrm{Q} 3$ = quartiles

*All diseases had been already present at diagnosis of breast cancer. Group 1: mild aortic stenosis; Group 2: mitral valve prolapse; compensated hypertonic heart and symptomatic angina pectoris; undefined cardiomyopathy

group) for continuous variables was tested with t-test, Welsch t-test, or Mann-Whitney test as appropriate. The assumption of normality was verified with Shapiro-Wilks test, and Bartlett test was used to test the assumption of variance equality.

The association between the two groups (left breast cancer and right breast cancer group) and categorical variables was tested with $\chi^{2}$ test, as well as with Yates continuity correction of Fischer exact test as appropriate.

A p-value of less than 0.05 was considered as statistically significant. The analysis was performed with $\mathrm{R}$ language for statistical computing ( $R$ version 3.0.1.).22

\section{Results}

\section{Patient characteristics}

There were 84 patients (48\%) in the left breast cancer group, and 91 patients (52\%) in the right breast cancer group. Median age was 59 (52-67) years in the left breast cancer group, and 55 (46-63) years in the right breast cancer group $(\mathrm{p}=0.009)$. Median observation time was 57 (37-71) months. Patients and tumour characteristics as well as the associated diseases are described in Table 1. Among all the patients, 35 of them $(20 \%)$ had arterial hypertension, but there were no significant differences between the two groups.

\section{Local and systemic treatments}

All patients received CT. Among all of them 95 patients (54.3\% of all the patients) received one of the following CT schemes: doxorubicin, cyclophosphamide (AC) / epirubicin, cyclophosphamide (EC) / 5-FU, doxorubicin, cyclophosphamide (FAC) / 5-FU, epirubicin, and cyclophosphamide (FEC) with a sequence of taxanes, and 69 patients (39.4\% of all the patients) received one of the following schemes: AC / EC / FAC / FEC without taxanes. Only 11 patients (6.3\% of all the patients) did not receive any anthracyclines (6 patients in the left breast cancer group and 5 patients in the right breast cancer group). None of the patients received concomitant anthracyclines and trastuzumab. There were no significant differences found in the CT schemes used, hormone therapies, and in the mean received cumulative doses of anthracyclines, taxanes, cyclophosphamide, and trastuzumab between the two groups. Systemic treatment is described in detail in Table 2.

Among all the patients, 39 patients $(79.4 \%$ of all the patients) were treated with 2D RT technique, and 25 patients $(14.3 \%)$ with 3D CRT technique. RT treatment features are presented in Table 3. 
TABLE 2. Systemic treatment and surgical characteristics

\begin{tabular}{|c|c|c|c|c|}
\hline & $\begin{array}{c}\text { All } \\
(\mathrm{N}=175)(\%)\end{array}$ & $\begin{array}{l}\text { Left BC Group } \\
(\mathrm{N}=84)(\%)\end{array}$ & $\begin{array}{l}\text { Right BC Group } \\
(\mathrm{N}=91)(\%)\end{array}$ & $P$ value \\
\hline $\begin{array}{l}\text { Anthracyclines } \\
\text { Cumulative dose- mg/m²BSA } \\
\text { (Median [Q1-Q3]) }\end{array}$ & 350 (292-499) & 352 (295-497) & 349 (290-499) & 0.799 \\
\hline $\begin{array}{l}\text { Taxanes } \\
\text { Cumulative dose- mg/m² BSA } \\
\text { (Median [Q1-Q3]) }\end{array}$ & $\begin{array}{c}297 \\
(276-594)\end{array}$ & $\begin{array}{c}297 \\
(281-422)\end{array}$ & $\begin{array}{c}298 \\
(273-768)\end{array}$ & 0.783 \\
\hline $\begin{array}{l}\text { Cyclophosphamide } \\
\text { Cumulative dose- mg/m²BSA } \\
\text { (Median [Q1-Q3]) }\end{array}$ & $\begin{array}{c}2316 \\
(1758-2924)\end{array}$ & $\begin{array}{c}2344 \\
(1763-2992)\end{array}$ & $\begin{array}{c}2268 \\
(1758-2829)\end{array}$ & 0.482 \\
\hline $\begin{array}{l}\text { CT Scheme } \\
\text { AC/EC/FAC/FEC + taxanes } \\
\text { AC/EC/FAC/FEC without taxanes } \\
\text { Other }\end{array}$ & $\begin{array}{l}95(54.3 \%) \\
69(39.4 \%) \\
11(6.3 \%)\end{array}$ & $\begin{aligned} 40 & (47.6 \%) \\
38 & (45.3 \%) \\
6 & (7.1 \%)\end{aligned}$ & $\begin{array}{l}55(60.4 \%) \\
31(34.1 \%) \\
5(5.5 \%)\end{array}$ & 0.235 \\
\hline $\begin{array}{l}\text { Endocrine therapy } \\
\text { Tamoxifen } \\
\text { Aromatase inhibitor } \\
\text { Other }\end{array}$ & $\begin{array}{l}39(22.3 \%) \\
45(25.7 \%) \\
10(5.7 \%)\end{array}$ & $\begin{aligned} 21 & (25 \%) \\
26 & (30.9 \%) \\
7 & (8.3 \%)\end{aligned}$ & $\begin{array}{l}18(19.8 \%) \\
19(20.8 \%) \\
3(3.3 \%)\end{array}$ & 0.652 \\
\hline $\begin{array}{l}\text { Trastuzumab } \\
\text { Cumulative dose- mg/kg BSA } \\
\text { (Median [Q1-Q3]) }\end{array}$ & $105(97-114)$ & $105(97-116)$ & $105(97-112)$ & 0.658 \\
\hline $\begin{array}{l}\text { Type of surgery } \\
\text { Mastectomy } \\
\text { Breast conserving surgery }\end{array}$ & $\begin{array}{l}91 \text { (52\%) } \\
84(48 \%)\end{array}$ & $\begin{array}{c}38(45.2 \%) \\
46(54.8)\end{array}$ & $\begin{array}{l}53(58.2 \%) \\
38(41.8 \%)\end{array}$ & 0.116 \\
\hline
\end{tabular}

$\mathrm{AC}=$ doxorubicin, cyclophosphamide $\mathrm{BC}=$ breast cancer; $\mathrm{BSA}=$ body surface area (The Du Bois formula was used for the calculation): $\mathrm{CT}=$ chemotherapy; $\mathrm{EC}=$ epirubicin, cyclophosphamide; $\mathrm{FAC}=5$-FU, doxorubicin, cyclophosphamide; FEC = 5-FU, epirubicin, and cyclophosphamide: Q1-Q3 = quartiles

TABLE 3. Radiotherapy treatment features

\begin{tabular}{|c|c|c|c|c|}
\hline & $\begin{array}{c}\text { All } \\
(N=175)(\%)\end{array}$ & $\begin{array}{l}\text { Left BC group } \\
(N=84)(\%)\end{array}$ & $\begin{array}{l}\text { Right BC group } \\
(\mathrm{N}=91)(\%)\end{array}$ & $p$ value \\
\hline $\begin{array}{l}\text { RT field* } \\
\text { Breast } \\
\text { Breast + scl } \\
\text { Thoracic wall } \\
\text { Thoracic wall + scl }\end{array}$ & $\begin{array}{c}70(40 \%) \\
17(9.7 \%) \\
17(9.7 \%) \\
71(40.6 \%)\end{array}$ & $\begin{array}{c}38(45.3 \%) \\
9(10.7 \%) \\
8(9.5 \%) \\
29(34.5 \%)\end{array}$ & $\begin{aligned} 32 & (35.2 \%) \\
8 & (8.8 \%) \\
9 & (9.9 \%) \\
42 & (46.1 \%)\end{aligned}$ & 0.434 \\
\hline $\begin{array}{l}\text { RT technique } \\
\text { 2D RT } \\
\text { 3D CRT } \\
\text { Electrons +/- photons }\end{array}$ & $\begin{array}{l}139(79.4 \%) \\
25(14.3 \%) \\
11(6.3 \%)\end{array}$ & $\begin{array}{c}69(82.1 \%) \\
12(14.3 \%) \\
3(3.6 \%)\end{array}$ & $\begin{array}{c}70(76.9 \%) \\
13(14.3 \%) \\
8(8.8 \%)\end{array}$ & 0.256 \\
\hline $\begin{array}{l}\text { RT scheme } \\
25 \times 2 \mathrm{~Gy} \\
17 \text { or } 18 \times 2.5 \mathrm{~Gy}\end{array}$ & $\begin{array}{l}14(84.6 \%) \\
27(15.4 \%)\end{array}$ & $\begin{array}{l}73(86.9 \%) \\
11(13.1 \%)\end{array}$ & $\begin{array}{l}75(82.4 \%) \\
16(17.6 \%)\end{array}$ & 0.540 \\
\hline
\end{tabular}

$\mathrm{BC}=$ breast cancer; $\mathrm{RT}=$ radiotherapy; $\mathrm{SCl}=$ periclavicular nodes; $2 \mathrm{D} \mathrm{RT}=$ two-dimensional radiotherapy; $3 \mathrm{D}$ CRT $=$ three-dimensional $\mathrm{conformal}$ radiotherapy

* parasternal lymph nodes were not included in the irradiated area

\section{Early cardiotoxicity parameters (LVEF and NT-proBNP)}

The analysis showed no statistically significant differences between initial and control LVEF in the observed groups. Data is presented in detail in Table 4 .
The time between the introduction of trastuzumab and the beginning of RT, the time between $\mathrm{LVEF}_{0}$ measurement and the time beetween $\mathrm{LVEF}_{0}$ and $\mathrm{LVEF}_{1}$ did not differ between the observed groups ( $p=0.596,0.506$ and 0.089 , respectively).

Overall, we found an important reduction of the LVEF (a decrease of LVEF for 10 percent points or 
TABLE 4. Analysis of the difference in left ventricular ejection fractions ( $\triangle$ LVEF)

\begin{tabular}{|c|c|c|c|c|}
\hline & $\begin{array}{c}\text { All } \\
(\mathrm{N}=175)\end{array}$ & $\begin{array}{l}\text { Left } B C \text { Group } \\
\quad(N=84)\end{array}$ & $\begin{array}{l}\text { Right BC Group } \\
\quad(N=91)\end{array}$ & $P$ value \\
\hline $\begin{array}{l}\operatorname{LVEF}_{0}(\%) \\
\quad \text { (Median [Q1-Q3]) }\end{array}$ & $65(60-69)$ & $65(61-70)$ & $63(59.5-67)$ & 0.0208 \\
\hline $\begin{array}{l}\operatorname{LVEF}_{1}(\%) \\
\quad(\text { Median [Q1-Q3]) }\end{array}$ & $66(62-70)$ & $67(64-70)$ & $65(60-70.5)$ & 0.117 \\
\hline $\begin{array}{l}\text { Analysis of } \Delta \text { LVEF } \\
\operatorname{LVEF}_{0}(\%)-\mathrm{LVEF}_{1}(\%)=\Delta \mathrm{LVEF} \\
(\text { Mean }[\mathrm{SD}])\end{array}$ & $\begin{array}{c}(n=149) \\
-2.22(8.69)\end{array}$ & $\begin{array}{c}(n=70) \\
-1.78(7.85)\end{array}$ & $\begin{array}{c}(n=79) \\
-2.60(9.4)\end{array}$ & $\begin{array}{c}0.562 \\
95 \% \mathrm{Cl}:-2.004-3.648\end{array}$ \\
\hline
\end{tabular}

$\mathrm{BC}=$ breast cancer; $\mathrm{Cl}=$ confidental interval; $\mathrm{LVEF}_{0}=$ measurement of LVEF before RT; $\mathrm{LVEF}_{1}$ - measurement of $\mathrm{LVEF}$ after the adjuvant treatment with $\mathrm{T}$; Q1-Q3 = quartiles; SD = standard deviation

more or a final value of LVEF < 50) in 9 patients (6\%) (4 patients in the left breast cancer and 5 in the right breast cancer group), of which 8 patients were classified as NYHA class 1.

Median NT-proBNP, measured after the completed treatment with trastuzumab, was 111.0 (56.7-182) ng/l in the left breast cancer group, and $90.0(58-170) \mathrm{ng} / \mathrm{l}$ in the right breast cancer group $(\mathrm{p}=0.545)$

\section{Echocardiographic parameters}

Echocardiographic parameters are presented in Table 5. A comparison of echocardiographic parameters showed that the patients who received $\mathrm{RT}$ to the left breast/thoracic wall did not have significantly worse systolic or diastolic left ventricular function.

We found significantly more pericardial effusions $(9[11 \%])$ in the left breast cancer group than in the right breast cancer group (1 [1\%]) $(p=0.007)$. The thickness of pericardial effusion was $>1 \mathrm{~cm}$ in 1 patient in the left breast cancer group, all others were $<1 \mathrm{~cm}$.

\section{Discussion}

Thanks to treatment with trastuzumab, patients with HER2 positive breast cancer nowadays live longer than ever. In the framework of the oncological treatment they received a very successful therapy that in many cases prevents cancer recurrence, but could also have an impact on their health and therefore on the quality of their life a few or many years after the treatment. It is very important to analyse such sequels of a treatment, especially if they could be successfully treated at the very beginning, and if the exacerbation could be stopped before it affects the quality of life.
Concomitant treatment with trastuzumab and RT has been a part of a standard adjuvant treatment of HER2 positive breast cancer at our institution since 2005, which means from the very beginning of the "adjuvant trastuzumab era". In that time 2D RT technique was used at our institution for breast cancer patients, and most patients from our study were irradiated with this technique. Later more accurate 3D CRT technique was available for adjuvant RT in breast cancer patients. None

TABLE 5. Echocardiografic parameters $(n=175)$

\begin{tabular}{|c|c|c|c|}
\hline & $\begin{array}{c}\text { Left BC Group } \\
(n=84) \\
\text { (median [Q1-Q3]) }\end{array}$ & $\begin{array}{c}\text { Right BC Group } \\
(n=91) \\
\text { (median [Q1-Q3]) }\end{array}$ & $p$ value \\
\hline LV EDD (cm) & $4.6(4.4-4.9)$ & $4.6(4.4-4.8)$ & $\begin{array}{c}0.913 \\
95 \% \mathrm{Cl}(-0.10-0.10)\end{array}$ \\
\hline LV ESD (cm) & $2.9(2.6-3.1)$ & $2.8(2.5-3.2)$ & $95 \%$ Cl $(-0.19-0.10)$ \\
\hline LA tr $(\mathrm{cm})$ & $3.4(3.2-3.8)$ & $3.4(3.2-3.7)$ & $\begin{array}{c}0.830 \\
95 \% \mathrm{Cl}(-0.10-0.10)\end{array}$ \\
\hline LA long (cm) & $4.4(4.0-4.8)$ & $4.5(4.2-4.6)$ & $\begin{array}{c}0.979 \\
95 \% \mathrm{Cl}(-0.10-0.10)\end{array}$ \\
\hline RA tr $(\mathrm{cm})$ & $3.2(3.0-3.6)$ & $3.4(3.0-3.7)$ & $\begin{array}{c}0.298 \\
95 \% \text { Cl }(-0.20-0.00)\end{array}$ \\
\hline RA long (cm) & $4.1(3.8-4.4)$ & $4.3(3.9-4.4)$ & $\begin{array}{c}0.226 \\
95 \% \mathrm{Cl}(-0.20-0.09)\end{array}$ \\
\hline LVEF (\%) & $68.5(64-74.2)$ & $68.0(63.0-72.5)$ & $\begin{array}{c}0.758 \\
95 \% \mathrm{Cl}(-2.0-3.00)\end{array}$ \\
\hline E/A & $1.07(0.80-1.23)$ & $1.08(0.87-1.32)$ & $\begin{array}{c}0.113 \\
95 \% \mathrm{Cl}(-0.18-0.02)\end{array}$ \\
\hline$E / E_{m}$ & $7.15(6.27-9.26)$ & $7.40(6.18-8.68)$ & $\begin{array}{c}0.918 \\
95 \% \mathrm{Cl}(-0.52-0.66)\end{array}$ \\
\hline s/d & $1.368(1.065-1.600)$ & 1.149 (0.94-1.35) & $\begin{array}{c}0.002 \\
95 \% \mathrm{Cl}(0.07-0.29)\end{array}$ \\
\hline TDI Sm (cm/s) & $8.0(7.0-9.1)$ & $8.0(7.0-9.1)$ & $\begin{array}{c}0.985 \\
95 \% \mathrm{Cl}(-0.50-0.50)\end{array}$ \\
\hline TDI Em (cm/s) & $10.0(7.82-11.37)$ & $10.0(8.05-11.8)$ & $\begin{array}{c}0.547 \\
95 \% \mathrm{Cl}(-0.10-0.50)\end{array}$ \\
\hline
\end{tabular}

$\mathrm{Cl}=$ confidental interval: $\mathrm{E} / \mathrm{A}=$ mitral valve annulus ratio of early diastolic and atrial flow velocities: $\mathrm{E} / \mathrm{E}_{\mathrm{m}}=$ ratio between the early diastolic blood flow velocitiy on the mitral valve annulus and early diastolic tissue Doppler velocity at the mitral ring; LA long - left atrial longitudinal diameter; LA $\mathrm{tr}=$ left atrial transversal diameter; LV EDD = left ventricular end diastolic diameter; LVEF = left ventricular ejection fraction; LV ESD = left ventricular end systolic diameter; $Q 1-Q 3=$ quartiles; RA long - right atrial longitudinal diameter; $\mathrm{RA} t \mathrm{tr}=$ right atrial transversal diameter; $\mathrm{s} / \mathrm{d}=$ ratio of systolic and diastolic blood flow velocities in the pulmonary vein, TDI Sm - systolic tissue Doppler velocity at the mitral ring; TDI Em = early diastolic tissue Doppler velocity at the mitral ring 
TABLE 6. Pericardial effusion

\begin{tabular}{cccccc}
\hline & ECHO & $\begin{array}{c}\text { All } \\
(\mathbf{N}=174)(\%)\end{array}$ & $\begin{array}{c}\text { Left BC Group } \\
(\mathbf{N}=83)(\%)\end{array}$ & $\begin{array}{c}\text { Right BC Group } \\
(\mathbf{N}=91)(\%)\end{array}$ & p value \\
\hline Pericard & $\begin{array}{c}\text { Normal } \\
\text { Effusion }\end{array}$ & $\begin{array}{c}164(94.3 \%) \\
10(5.7 \%)\end{array}$ & $\begin{array}{c}74(89 \%) \\
9(11 \%)\end{array}$ & $\begin{array}{c}90(99 \%) \\
1(1 \%)\end{array}$ & 0.007 \\
\hline
\end{tabular}

$\mathrm{BC}=$ breast cancer $\mathrm{ECHO}=$ echocardiography

of the patients included in the study received RT specifically to the parasternal lymph nodes. This fact is important for the interpretation of the results, because $\mathrm{RT}$ in that region may raise the dose received by the heart. ${ }^{23}$

All the patients included in the study were treated with CT. Only 11 patients did not receive CT with anthracyclines, which is not surprising, especially if taking into account the well-known benefits of the anthracycline treatment. ${ }^{24}$ There were no significant differences in the CT scheme used, endocrine therapy, and in the mean received cumulative doses of anthracyclines, taxanes, cyclophosphamide, and trastuzumab between the two groups $(p>0.05)$. These results suggest that cardiotoxic effect of specific systemic oncological treatment was similar in both groups that were analysed. In the framework of the adjuvant treatment received by the patients, the only factor that could affect the difference in cardiotoxic parameters measured in both groups was the cardiotoxic effect of the adjuvant RT.

The prevalence of smoking, hyperlipidemia, and arterial hypertension was approximately the same in both groups (around $20 \%$ ). Only 3 patients had diabetes, all of them had breast cancer of the right breast. Among all the patients, 4 patients had already been diagnosed with heart diseases at the time of breast cancer diagnosis (specified in Table 1). One 70-year-old patient acquired atrial fibrillation two years after being diagnosed with breast cancer, but she had had arterial hypertension for 18 years already. According to this data, the influence of cardiovascular disease predisposing factors was similar in both groups.

The differences in $\triangle$ LVEF between the two groups were not statistically significant. The acquired data shows that the median value of the LVEF in both groups was slightly lower at the beginning of the treatment in comparison with the LVEF value measured after the treatment. This could be explained by the time that passed from the introduction of trastuzumab to the measurement of LVEF (mean time 62 days in the left breast cancer group and 66 days in the right breast cancer group. $p=0,591)$. It was reported that LVEF value could reversibly decrease during treatment with trastuzumab. ${ }^{25}$

Among all the patients, we found an important reduction of the LVEF (a decrease of LVEF for 10 percent points or more or a final value of LVEF < $50)$ in 9 patients (6\%). There were more such patients in the right breast cancer group $(6.3 \%)$ than in the left breast cancer group (5.7\%); therefore, we concluded that left breast/chest wall irradiation was not the key factor that would significantly affect the reduction of LVEF.

The analysis showed no statistically significant differences in NT-proBNP between the two groups. According to the instructions of the diagnostic test manufacturer, the values of the NTproBNP below $125 \mathrm{ng} / \mathrm{l}$ exclude heart failure, so we decided to mark all the values of NT-proBNP $125 \mathrm{ng} / \mathrm{l}$ or higher as an event. There were no significant differences in the number of such events in both groups. Among all the patients there were 69 patients (39\%) with NT-proBNP $125 \mathrm{ng} / \mathrm{l}$ or more, 35 patients $(41.7 \%)$ in the left breast cancer group, 34 patients $(37.4 \%)$ in the right breast cancer group; $p=0.669$. Based on these results we concluded that left breast/chest wall irradiation did not have a considerable impact on the measured values of NTproBNP after the treatment had been completed.

Certain parameters of left ventricular diastolic dysfunction, such as mitral valve E/A ratio, E/Em ratio, and pulmonary vein $\mathrm{s} / \mathrm{d}$ ratio, are more sensitive and can be detected before the LVEF reduction. Left ventricular diastolic dysfunction therefore can represent an early sign of cardiotoxicity, and thus, since it is more timely, proves to be more effective than LVEF estimation. ${ }^{26,27}$ Among patients included in our study $42 \%$ had left ventricular diastolic dysfunction, mostly mild. One patient in the left breast cancer and 5 patients in the right breast cancer group had moderate diastolic dysfunction, none of the patients had severe diastolic dysfunction. Baseline diastolic function was not determined. We found significantly lower s/d ratio in the right breast cancer group, suggesting worse diastolic function compared to the left breast cancer group. 
Since s/d ratio is largely dependent on the hemodynamic status it cannot be used as a sole diastolic function predictor. There were no significant differences in other left ventricular diastolic function parameters between the observed groups. That is why we presumed that RT had no significant influence on the left ventricular diastolic function in the observed time interval.

The analysis of echocardiographic parameters showed that patients in both groups had heart cavities of normal size and a normal systolic function of the left ventricle. The patients irradiated on the left breast/thoracic wall did not have significantly worse systolic or diastolic function of the left ventricle.

The data showed that the patients with left breast cancer had significantly higher incidence of pericardial effusion after the stated observation time. It is well known that irradiation could damage pericardium and that acute pericarditis is the most common heart damage caused by irradiation. It is rare and most commonly develops in the first year after the RT treatment. ${ }^{28}$

In conclusion, we did not find any significant differences in the early parameters of cardiotoxicity (LVEF, NT-proBNP) between the two observed groups. The patients with the left breast cancer that were irradiated on the left breast/thoracic wall four and a half years after the treatment did not have significantly worse systolic or diastolic function of the left ventricle compared to the patients with the right breast cancer that were irradiated on the right breast/thoracic wall, but, left breast cancer patients had significantly higher incidence of pericardial effusion. RT did not have an important impact on the function of the left ventricle after the stated observation time.

So far, this is the first study evaluating early cardiotoxicity with the echocardiographic parameters and NT-proBNP in breast cancer patients after the completed concomitant treatment with RT and trastuzumab.

Our observation of higher incidence of pericardial effusion in left breast cancer was limited by a small number of included patients. In the future studies with a larger number of patients are to be carried out to confirm our findings.

In the following studies, it would be necessary to determine whether the changes in the pericardium are more frequent, more pronounced, or maybe last longer if patients receive RT concurrently with trastuzumab.

\section{References}

1. Cameron D, Piccart-Gebhart MJ, Gelber RD, Procter M, Goldhirsch A, de Azambuja E, et al. Herceptin Adjuvant (HERA) Trial Study Team. 11 years' follow-up of trastuzumab after adjuvant chemotherapy in HER2-positive early breast cancer: final analysis of the HERceptin Adjuvant (HERA) trial. Lancet 2017; 389: 1195-205. doi: 10.1016/S0140-6736(16)32616-2

2. Pinto AC, Ades F, de Azambuja E, Piccart-Gebhart M. Trastuzumab for patients with HER2 positive breast cancer: delivery, duration and combination therapies. Breast 2013; 22: 152-5. doi: 10.1016/j.breast.2013.07.029

3. Mathew A, Romond EH. Systemic therapy for HER2-positive early-stage breast cancer. Curr Probl Cancer 2016; 40: 106-16. doi: 10.1016/j.currprobIcancer.2016.09.002

4. Matos E, Zakotnik B, Kuhar CG. Effectiveness of adjuvant trastuzumab in daily clinical practice. Radiol Oncol 2014; 48: 403-7. doi: 10.2478/ raon-2013-0081

5. Zamorano JL, Lancellotti P, Muñoz DR, Aboyans V, Asteggiano R, Galderisi M, et al. 2016 ESC Position Paper on cancer treatments and cardiovascular toxicity developed under the auspices of the ESC Committee for Practice Guidelines: The Task Force for cancer treatments and cardiovascular toxicity of the European Society of Cardiology (ESC). Eur Heart J 2016; 37: 2768-801. doi: 10.1093/eurheartj/ehw211

6. Jawa Z, Perez RM, Garlie L, Singh M, Qamar R, Khandheria BK, et al. Risk factors of trastuzumab-induced cardiotoxicity in breast cancer: a meta-analysis. Medicine (Baltimore) 2016; 95: e5195. doi: 10.1097/ MD.0000000000005195

7. Piccart-Gebhart MJ, Procter M, Leyland-Jones B, Goldhirsch A, Untch $\mathrm{M}$, Smith I, et al. Trastuzumab after adjuvant chemotherapy in HER-2 positive breast cancer. N Engl J Med 2005; 353: 1659-72. doi: 10.1056/ NEJMoa052306

8. Darby SC, McGale P, Taylor CW, Peto R. Long-term mortality from heart disease and lung cancer after radiotherapy for early breast cancer: prospective cohort study of about 300,000 women in US SEER cancer registries. Lancet Oncol 2005; 6: 557-65. doi: 10.1016/S1470-2045(05)70251-5

9. Henson KE, McGale P, Taylor C, Darby SC. Radiation-related mortality from heart disease and lung cancer more than 20 years after radiotherapy for breast cancer. Br J Cancer 2013; 108: 179-82. doi: 10.1038/bjc.2012.575

10. Sardar P, Kundu A, Chatterjee S, Nohria A, Nairooz R, Bangalore S, et al. Long-term cardiovascular mortality after radiotherapy for breast cancer: a systematic review and meta-analysis. Clin Cardiol 2017; 40: 73-81. doi: $10.1002 /$ clc. 22631

11. Jacob J, Belin L, Gobillion A, Daveau-Bergerault C, Dendale R, Beuzeboc P, et al. [Prospective monocentric study of the toxicity and the efficacy of concurrent trastuzumab and radiotherapy].[French]. Cancer Radiother 2013; 17: 183-90. doi: 10.1016/j.canrad.2012.12.006

12. Keefe DL. Trastuzumab-associated cardiotoxicity. Cancer 2002; 95: 1592 600. doi: $10.1002 / \mathrm{cncr} .10854$

13. Perez EA, Rodeheffer R. Clinical cardiac tolerability of trastuzumab. J Clin Oncol 2004; 22: 322-9. doi: 10.1200/JCO.2004.01.120

14. Fiuza M. Cardiotoxicity associated with trastuzumab treatmentof HER2+ breast cancer. Adv Ther 2009; 26(Suppl 1): S9-17. doi: 10.1007/s12325009-0048-z

15. Guarneri V, Lenihan DJ, Valero V, Durand JB, Broglio K, Hess KR, et al. Longterm cardiac tolerability of trastuzumab in metastatic breast cancer: the M.D. Anderson Cancer Center experience. J Clin Oncol 2006; 24: 4107-15. doi: 10.1200/JCO.2005.04.9551

16. Steel GG. Basic clinical radiobiology. 3rd edition. London: Arnold; 2002. p. 217-39.

17. Zethelius B, Berglund L, Sundström J, Ingelsson E, Basu S, Larsson A, et al. Use of multiple biomarkers to improve the prediction of death from cardiovascular causes. N Engl J Med 2008; 358: 2107-16. doi: 10.1056/ NEJMoa0707064

18. Kinnunen $\mathrm{P}$, Vuolteenaho $\mathrm{O}$, Ruskoaho $\mathrm{H}$. Mechanisms of atrial and brain natriuretic peptide release from rat ventricular myocardium: Effect of streching. Endocrinology 1993; 132: 1961-70. doi: 10.1210/endo.132.5.8477647 
19. Raymond I, Groenning BA, Hildebrandt PR, Nilsson JC, Baumann M Trawinski J, et al. The influence of age, sex and other variables on the plasma level of $\mathrm{N}$-terminal pro brain natriuretic peptide in a large sample of the general population. Heart 2003; 89: 745-51.

20. Marinko T, Dolenc J, Bilban-Jakopin C. Cardiotoxicity of concomitant radiotherapy and trastuzumab for early breast cancer. Radiol Oncol 2014; 48: 105-12. doi: 10.2478/raon-2013-0040

21. Marinko T. Impact of concurrent radiotherapy and treatment with trastuzumab on cardiotoxicity of breast cancer patients. [Dissertation]. Ljubljana: Faculty of Medicine, University of Ljubljana; 2014.

22. $\mathrm{R}$ Core Team. R: A language and environment for statistical computing Vienna: R Foundation for Statistical Computing; 2013. [cited 2017 Nov 15]. Available at http://www.R-project.org/

23. Hooning MJ, Botma A, Aleman BM, Baaijens MH, Bartelink H, Klijn JG, et al. Long-term risk of cardiovascular disease in 10-year survivors of breast cancer. J Nat/ Cancer Inst 2007; 99: 365-75. doi: 10.1093/jnci/djk064

24. National Comprehensive Cancer Network Clinical Practice Guidelines in Oncology: Breast Cancer. Version 2.2017. [cited 2017 Nov 7]. Available at: https://www.nccn.org/professionals/physician_gls/pdf/breast.pdf

25. Ewer MS, Tan-Chiu E. Reversibility of trastuzumab cardiotoxicity: is the concept alive and well? J Clin Oncol 2007; 25: 5532-3. doi: 10.1200/ ICO.2007.14.0657

26. Giannuzzi $\mathrm{P}$, Temporelli $\mathrm{PL}$, Bosimini E, Silva $\mathrm{P}$, Imparato $\mathrm{A}$, Corrà $\mathrm{U}$, et al. Independent and incremental prognostic value of Doppler-derived mitral deceleration time of early filling in both symptomatic and asymptomatic patients with left ventricular dysfunction. J Am Coll Cardiol 1996; 28: 38390. doi: 10.1016/0735-1097(96)00163-5

27. Suzuki J, Yanagisawa A, Shigejama T, Tsubota J, Yasumura T, Shimoyama $\mathrm{K}$, et al. Early detection of anthracycline-induced cardiotoxicity by radionuclide angiocardiography. Angyology 1999; 50: 37-45. doi: 10.1177/000331979905000105

28. Hall EJ, Giaccia AJ. Radiobiology for the radiologist. Chapter 20. 7th edition. Philadelphia: Lippincott Williams \& Wilkins, Wolters Kluwer; 2012. p 343. 